
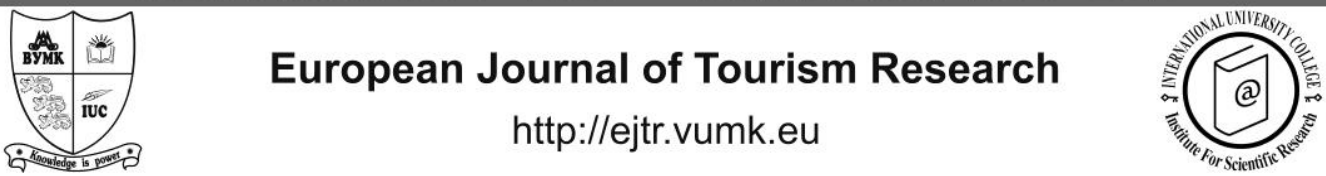

\title{
Lisch, R. (2014). Measuring Service Performance. Practical Research for better quality. Gower Publishing Ltd., England. ISBN 9781472411921 (e-book). 213 pp.
}

\author{
Reviewed by Maya Ivanova ${ }^{1}$
}

Received: 15/10/2014

\begin{abstract}
${ }^{1} \mathrm{PhD}$, Lecturer at Tourism and Hospitality Department, International University College, Bulgaria, email: maya.ivanova@vumk.eu
\end{abstract}

(c) 2015 International University College. All rights reserved

Citation Lisch, R. (2014). Measuring Service Performance. Practical Research for better quality. Gower Publishing Ltd., England. ISBN 9781472411921 (e-book). 213 pp. Reviewed by Maya Ivanova, European Journal of Tourism Research 9, pp. 150-151

Service industry is perceived to be a multifaceted industry with quite diverse features. It is a real challenge to properly describe, standardise and/or reproduce any service, with a guarantee for its permanent quality. For this purpose, profound knowledge is required of both the way the services are provided, and the way they are perceived from the clients. In order to gain such knowledge, one has to examine deeply services, using the various research methods and conducting them properly. Exactly with this idea Ralf Lisch elaborates his book "Measuring service performance. Practical guide research for better quality".

The book is organised in 9 chapters, each of them consisting of several sub-sections; there are 5 figures and 7 tables. At first glance, it is quite an extraordinary book, out of the standard perceptions of "research methodology guide". The goal of the author goes beyond the traditional framework of the research process. In the very beginning he warns the reader not to expect any Handbook or ready-made advice on how to implement a research. On the contrary - it is a challenge, 150 that the author throws towards the reader, in order to drag him out of the conventional perception of the general concepts like "service", "quality", "research", etc. , and make him perceive them in a bit a different angle. In this regard, the book is written much more as a philosophical paper, than as an ordinary academic or professional book. Although the book is targeted to practitioners, rather than to academicians, it requires much more sophisticated skills and knowledge to understand the philosophy and final aim of the author. Dr Lisch's thorough vision of the service industry, research methods and the process of studying and measuring services allows the reader to have a broader overview. $\mathrm{He}$ presents his own perceptions of the universal terms and concepts, but putting them in the context of both business and academic approach, garnished with a philosophical flavour.

The ultimate goal of the book to deliver better understating of the quality research leads to total reconsideration of quality research with more focus on its contents, instead of on the methods and methodology. "Service excellence 
deserves research excellence" (p. 183) is the guiding light that $\mathrm{Dr}$ Lisch claims throughout his whole book. In the first two chapters (Chapter 1. Introduction and Chapter 2. Services and Challenges) the author deploys his rationale regarding researching services and their quality, and builds his premises on much broader ground, stepping on economics, psychology and sociology. The explanations and reasoning do not sound pompous or complicated, but they are rather simply described and justified. It is interesting to note, that Dr. Lisch gives the etymological roots of all the key terms, continuously approaching the reader to the current meaning of the words and how the transformation of the initial meaning took place. In this way he set much stronger basis for his arguments, revealing in front of the reader deeper and broader view of the concept.

Another unusual feature of the book is the reference list - it consists of 65 sources, most of which are very old (more than 40 years ago), even including several seminal works of famous philosophers like Machiavelli and Achenwall, dating from 2-4 centuries ago. The aim is to identify the very first sources, mentioning or defining any of the terms. Furthermore, by citing such seminal works and philosophers, the author persuades the reader how old the issue is, or how long ago a certain problem was stated and it still does not find a fixed solution. In this way a different side of a concept is provided, yet the same, but differentiated from the common understandings. It is the "epistemological approach" that the author employs, in order to emphasise that it is more important to know how to gain a better knowledge, than to receive directly a ready knowledge. In the same vein he argues, that the science is used publicly only as an external source to provide evidence for supporting or rejecting the specific interests, norms and wishes of suppliers, customers, media actors. Seen from this point of view, the aim of the book is to facilitate the practitioners to implement the quality research and measurements by themselves, thus to handle and improve the quality of their services/products.

Further (Chapters 3-8), the author follows the well-known stages of the research process, and again the focus is from another side - not on the empirical research and statistics, but on the methodological approach. Therefore, the structure of the book is a reflection of the research process. The rules and principles of conducting a research are not just prescribed, but they are largely explained and justified, using business jargon and common terms. "It is the art of consumer information to translate a scientific report into readable, easy to digest and at the same time relevant information" ( $p$. 28).

Dr. Lisch analyses the complexity, the objectivity, the relevance and the reliability of the research, elaborating for each of them his own understanding and interpretation. For example, he predisposes certain terms, like "methods" vs. "methodology", "methods" and "models", "reliability" and "validity", "adequacy" and "relevance", verifying the distinction not only in their definitions, but mostly what they actually mean in in the real world.

The author succeeds to go beyond the generally set framework of research, still remaining close to the particular needs and problems, met by the practitioners. In between the text stand some verified universal truths, some insights and even some inspiring thoughts that make the reader feel the deeper view behind the particular ideas in the book.

Overall, I would highly recommend this book for everyone, who has already implemented some research work, and have struggled to understand WHY the research follows the particular methodology. Nevertheless, in my opinion the book aims at a comparatively narrow audience, because although the language is informal and understandable, one needs a broader background and certain practical experience, in order to properly understand and really appreciate this amazing book. 